Quim. Nova, Vol. 32, No. 2, 498-502, 2009

\title{
ESTUDO COMPARATIVO ENTRE AS METODOLOGIAS PRECONIZADAS PELO CLSI E PELO EUCAST PARA AVALIAÇÃO DA ATIVIDADE ANTIFÚNGICA
}

\author{
Marcos Aurélio Stoppa, Luciana Assirati Casemiro, Adriana Helena Chicharo Vinholis, Wilson Roberto Cunha, Márcio \\ Luis Andrade e Silva e Carlos Henrique Gomes Martins* \\ Universidade de Franca, 14404-600 Franca - SP, Brasil \\ Niege Araçari Jacometti Cardoso Furtado \\ Faculdade de Ciências Farmacêuticas de Ribeirão Preto, Universidade de São Paulo, 14040-903 Ribeirão Preto - SP, Brasil.
}

Recebido em 2/4/08; aceito em 8/8/08; publicado na web em 5/2/09

\begin{abstract}
COMPARATIVE STUDY OF THE RECOMMENDED METHODOLOGIES BY CLSI AND EUCAST FOR ACTIVITY EVALUATION ANTIFUNGAL. The international organizations CLSI and EUCAST developed reference methodologies for activity evaluation antifungal. The aim of this work was to compare the recommended methodologies by the CLSI and EUCAST in the antifungal activity evaluation of crude extracts of Azadirachta indica and green propolis. The results showed that the MIC values determined by the EUCAST methodology were smaller than that determined by the CLSI. Nevertheless, both methodologies were satisfactory to detect and evaluate antifungal activity of the crude extracts and isolated compounds. The EUCAST methodology showed advantage by making possible to obtain results in less time.
\end{abstract}

Keywords: antifungal activity; CLSI; EUCAST.

\section{INTRODUÇÃO}

Os testes de susceptibilidade às drogas antifúngicas tornaram-se importantes, principalmente devido ao aumento de sérias infecções fúngicas e ao concomitante aparecimento de resistência aos agentes antifúngicos. ${ }^{1}$ Estes testes podem ser usados não somente na pesquisa de sensibilidade aos antimicrobianos, como também na busca por novos fármacos pela verificação da atividade antifúngica de amostras complexas, como extratos vegetais, e de substâncias puras. ${ }^{2-4}$ As metodologias para a avaliação da atividade antifúngica de produtos naturais são variáveis, sendo realizadas a bioautografia, a difusão em ágar e a diluição em ágar e caldo. ${ }^{5}$

A metodologia proposta pela organização americana Clinical and Laboratory Standards Institute (CLSI, anteriormente denominada Nacional Committee for Clinical Laboratory Standards, NCCLS) para a avaliação da atividade antifúngica de substâncias puras é a diluição em caldo, que apresenta a grande vantagem de propiciar alta reprodutibilidade entre os laboratórios. Entretanto, um problema a ser solucionado é a interpretação da leitura do crescimento trailing, a qual ocorre na leitura para a determinação dos valores de Concentração Inibitória Mínima (CIM) em leveduras, utilizando a técnica de microdiluição em caldo. ${ }^{6}$

O termo trailing (arraste) é usado para descrever o reduzido, mas persistente crescimento que alguns isolados de Candida spp. e Cryptococcus neoformans apresentam in vitro, após entrarem em contato com as drogas antifúngicas azólicas. Estima-se que esse fenômeno ocorra com aproximadamente 5\% dos isolados de Candida spp. ${ }^{6}$ Esse crescimento trailing pode ser tão vigoroso que faz com que um isolado seja interpretado como susceptível (S) após 24 h de incubação, mas se apresente como resistente (R) após 48 h. Dois estudos deste fenômeno empregados em candidíase murina demonstraram que o resultado avaliado nas primeiras $24 \mathrm{~h}$ era consistente com a resposta para o tratamento in vivo. ${ }^{7}$

\footnotetext{
*e-mail:martinsc@unifran.br
}

O ensaio recomendado para avaliação da atividade antifúngica de substâncias puras pela técnica da microdiluição em caldo, pela organização européia Antifungal Susceptibility Testing Subcommittee of the European Committee on Antibiotic Susceptibility Testing (AFST-EUCAST), ${ }^{8}$ é baseado nos procedimentos da referência CLSI M27-A2, ${ }^{9}$ mas com algumas modificações a fim de se obter maior exatidão na determinação dos valores de CIM. Estudos têm confirmado que a modificação do documento CLSI M27-A2 ${ }^{9}$ com a suplementação do meio RPMI 1640 com $2 \%$ de glicose no meio de cultura $^{8}$ tornou a metodologia mais vantajosa, por reduzir o tempo de incubação necessário ( 24 h) para se obter um crescimento suficiente para a determinação dos valores de CIM. ${ }^{10-14}$

Nas últimas décadas, a busca por novos agentes antimicrobianos, principalmente de fontes naturais, vem ganhando destaque. Neste sentido, os vegetais constituem uma enorme e importante fonte de produtos naturais que são biologicamente ativos, sendo que muitos destes podem ser utilizados como modelos para a síntese de inúmeros fármacos. ${ }^{15}$ Rios et al. ${ }^{16}$ revisaram os mais relevantes artigos desta área publicados entre os anos de 1978 e 1988, compilando uma lista de 75 espécies na qual estabeleceram a atividade dos extratos e dos constituintes responsáveis por essa atividade. Outros estudos têm demonstrado que produtos naturais oriundos de plantas apresentam atividade contra linhagens de patógenos resistentes aos antibióticos, bem como demonstram ter efeito sinérgico. ${ }^{17,18}$

Azadirachta indica A. juss, também conhecida por Melia indica Brandis, o nim indiano, pertencente à família Meliaceae, tem despertado o interesse de vários pesquisadores, pois seus constituintes bioativos são utilizados na forma de pós, extratos aquosos e/ou orgânicos (metanólico, etanólico, acetônico, clorofórmico, hexânico), óleos e pasta, além de frações, as quais são parcialmente purificadas e contêm majoritariamente o limonóide chamado azadiractina. ${ }^{19}$ Segundo Schmutterer, ${ }^{20}$ o local de origem, assim como a idade das sementes e o solvente utilizado na extração podem causar variações nos teores dos princípios ativos e, conseqüentemente, em suas atividades biológicas.

Govindachari et al. ${ }^{21}$ relataram que as frações do nim que 
apresentam atividade antifúngica contêm combinações principais de 6-diacetilnimbina, azadiradiona, nimbina e epoxiazadiradiona, sendo que com exceção da 6-diacetilnimbina, todos os demais não apresentaram atividade considerável quando analisados isoladamente. Todavia, quando combinados e testados, esses compostos mostraram boa atividade antifúngica, o que indica possíveis efeitos sinérgicos.

Dentre as ações antifúngicas, Hussain e Gorsi ${ }^{22}$ e Fabry et al..$^{23}$ relataram que $A$. indica apresenta atividade fungicida e fungistática contra Candida spp. Charmaine-Lloyd et al. ${ }^{24}$ relataram o uso do extrato de A. indica contra 15 isolados de Candida spp. de pacientes portadores de Human Immunodeficiency Virus (HIV); desse total, A. indica apresentou boa atividade contra 13 isolados desse gênero leveduriforme.

A própolis verde, a qual apresenta composição química complexa, também é reconhecida pelo potencial antimicrobiano. Os componentes predominantes na composição da resina da própolis verde são os fenilpropanóides, entre estes os derivados do ácido cinâmico, os compostos prenilados (em média de 8 a 10\%) e os ácidos aromáticos, os quais têm ações antitumoral, ${ }^{25}$ antifúngica, ${ }^{26}$ antibacteriana, ${ }^{27}$ antioxidante ${ }^{28}$ e antiviral. ${ }^{29}$ Marcucci et al. ${ }^{30}$ citam os compostos prenilados como os principais constituintes da própolis verde e relatam que as atividades antibacteriana e antifúngica destes compostos podem ser aumentadas com o aumento do número de resíduos prenilados na molécula.

Assim, o objetivo deste trabalho foi comparar as metodologias preconizadas pelo CLSI e pelo EUCAST normatizadas nos documentos M-27A e E. Dis. 7.1, respectivamente, para avaliação da atividade antifúngica de extratos brutos de Azadirachta indica e própolis verde.

\section{PARTE EXPERIMENTAL}

\section{Coleta e identificação do vegetal Azadirachta indica e aquisição da própolis verde}

As folhas de nim foram obtidas a partir de espécies com 3 anos de cultivo em condições de campo, oriundas de sementes fornecidas pelo Instituto Agronômico de Campinas (IAC) e cultivadas no município de Piumhi (MG). As exsicatas foram preparadas e depositadas no herbário da Universidade do Estado de Minas Gerais, em Passos (MG).

A amostra de própolis coletada em Oliveira - MG foi fornecida pelo Prof. Dr. J. K. Bastos, da Faculdade de Ciências Farmacêuticas de Ribeirão Preto, Universidade São Paulo.

\section{Obtenção dos extratos}

As folhas de nim (1,0 kg), após secagem em estufa com circulação de ar a $40{ }^{\circ} \mathrm{C}$, foram moídas e extraídas através de maceração com etanol/água $(4: 1 \mathrm{v} / \mathrm{v})$ por 3 semanas, à temperatura ambiente. Após remoção dos solventes em evaporador rotatório obteve-se o extrato hidroalcóolico bruto (120 g). Por sua vez, o extrato de própolis foi preparado a partir da amostra bruta proveniente de Oliveira (MG). Um quilograma da amostra de própolis verde foi mantido em congelador por 3 dias e, em seguida, foi triturado em liquidificador até pó fino, usando tamis de 16 mesh para homogeneização do pó. O pó obtido foi submetido à extração por maceração em etanol-água (7:3 $\mathrm{v} / \mathrm{v})$ por $24 \mathrm{~h}$ à temperatura ambiente, seguida por filtração em funil de Büchner. O resíduo foi novamente levado à maceração por mais $24 \mathrm{~h}$, no mesmo solvente, enquanto o filtrado foi concentrado em rotaevaporador. Repetiu-se o processo de maceração e filtração por mais três vezes, obtendo-se o extrato bruto (906 g).

\section{Ensaios biológicos}

Como controle da metodologia para as técnicas preconizadas pelo CLSI e pelo EUCAST, foi utilizado o controle positivo (fluconazol), o qual foi primeiramente solubilizado em DMSO e depois diluído. O DMSO foi utilizado como controle negativo para todas as leveduras, tendo em vista que o mesmo foi o diluente de escolha para os extratos testados.

Foram preparadas soluções do extrato bruto do nim e da própolis verde contendo $4 \mathrm{mg} / \mathrm{mL}$ em dimetilsulfóxido (DMSO) a 20\%. Em seguida, estas soluções foram diluídas em concentrações que variaram de 100 a $1600 \mu \mathrm{g} / \mathrm{mL}$.

Os ensaios foram realizados com os extratos brutos e com o fluconazol como controle positivo em DMSO $(0,125$ a $64 \mu \mathrm{g} / \mathrm{mL})$, utilizando-se três cepas padrão (C. albicans, $C$. parapsilosis e $C$. krusei) provenientes da American Type Culture Collection (ATCC) e 14 isolados clínicos (cepas isoladas de indivíduos submetidos à hemodiálise e de indivíduos hígidos doadores de sangue). Para a obtenção do inóculo, as cepas e os isolados clínicos foram repicados em meio de cultura ágar Sabouraud dextrose (Difco Labs, Detroit, Mich, USA) e incubados a $35^{\circ} \mathrm{C}$ em estufa bacteriológica por $24 \mathrm{~h}$.

Para assegurar a reprodutibilidade dos ensaios, a quantidade de inóculo a ser utilizada foi padronizada. Inicialmente preparou-se uma escala de 0,5 de McFarland, segundo Bier. ${ }^{31}$ Para isso, adicionou-se $0,5 \mathrm{~mL}$ de solução aquosa de cloreto de bário a $1 \%$ em $99,5 \mathrm{~mL}$ de solução aquosa de ácido sulfúrico a $1 \%$. Em seguida, transferiram-se $2 \mathrm{~mL}$ dessa suspensão para uma cubeta espectrofotométrica. A calibração da transmitância em $100 \%$ no espectrofotômetro usando um comprimento de onda de $530 \mathrm{~nm}$ foi realizada com água destilada. A leitura da suspensão de 0,5 de McFarland forneceu uma transmitância de $76 \%$. Assim, todas as suspensões de leveduras foram ajustadas na mesma transmitância.

\section{Avaliação da concentração inibitória mínima (CIM), segundo a técnica de microdiluição em caldo preconizada pelo CLSI, documento M27-A2 $^{9}$}

Com a utilização de uma agulha de platina esterilizada, foram transferidas culturas de $24 \mathrm{~h}$ das leveduras cultivadas em ágar Sabouraud dextrose (Difco). O meio de cultura utilizado foi o meio líquido RPMI 1640, para a determinação da susceptibilidade de leveduras aos antifúngicos. Este meio foi preparado numa solução tampão MOPS (Acros Organics, Geel, Turnhout, Bélgica) 0,165 M. A mistura foi corrigida com hidróxido de sódio até atingir $\mathrm{pH}$ 7. A seguir, o meio foi esterilizado por filtração com uma membrana de porosidade de $0,22 \mu \mathrm{m}$ (Millipore, Billerica, MA, USA) e posteriormente armazenado a uma temperatura entre 2 e $5{ }^{\circ} \mathrm{C}$. Foram utilizadas microplacas com 96 orifícios e cada orifício recebeu o inóculo, o meio de cultura e as soluções dos extratos diluídos, de tal forma que o volume final fosse de $100 \mu \mathrm{L}$. Para o controle da metodologia, foi utilizada uma solução de fluconazol (controle positivo), onde as concentrações avaliadas variaram de 0,125 a $64 \mu \mathrm{g} / \mathrm{mL}$. Também foram realizados os seguintes controles: controle de esterilidade do caldo RPMI 1640 (Gibco); controle do inóculo, o qual apresentou crescimento total devido à ausência do controle positivo, controles de esterilidade dos extratos brutos, bem como dos padrões positivos e negativos.

Com uma agulha de platina esterilizada, transferiram-se culturas de $24 \mathrm{~h}$ de leveduras para tubos contendo $2 \mathrm{~mL}$ de solução de cloreto de sódio a $0,85 \%$. Segundo os critérios do CLSI, foram efetuadas diluições sucessivas em tubo no caldo RPMI 1640 (Gibco), obtendose uma quantidade final de inóculo de $1,2 \times 10^{3} \mathrm{UFC} / \mathrm{mL}$.

Logo após a micropipetagem dos inóculos, do meio de cultura e dos controles, as microplacas foram tampadas e incubadas a $35^{\circ} \mathrm{C}$ 
por 48 h, sem agitação. Após o período de incubação, como procedimento opcional a esta técnica, foram adicionados em cada orifício das placas $15 \mu \mathrm{L}$ de resazurina (Sigma, ST. Louis, MO, USA) a 0,01\% em solução aquosa esterilizada. Após $4 \mathrm{~h}$ de reincubação, a leitura foi realizada. A resazurina (7-hidroxi-3H-fenoxazina-3-ona-10-óxido) de cor azul é oxidada na presença de células viáveis à resofurina, substância de coloração vermelha, facilitando a verificação da presença de crescimento microbiano. ${ }^{32}$ Desta forma, foi possível determinar a menor concentração de cada extrato bruto capaz de inibir o crescimento dos microrganismos indicadores.

Avaliação da concentração inibitória mínima (CIM), segundo a técnica de microdiluição em caldo preconizada pelo EUCAST $^{8}$

A etapa de preparo do meio de cultura foi idêntica ao do preconizado pelo CLSI, com exceção da adição de $18 \mathrm{~g}$ de glicose por litro de caldo RPMI 1640 (Gibco), a fim de que o mesmo apresentasse uma concentração final por litro de 2\% de glicose (RPMI $16402 \%$ G).

Para esse experimento, todos os procedimentos foram os mesmos usados no protocolo do CLSI, incluindo os controles da metodologia e sendo somente alterados os seguintes procedimentos: o inóculo, o qual passou a ter uma concentração final no orifício da placa de 1,2 x $10^{5} \mathrm{UFC} / \mathrm{mL}$, o tempo de leitura $(24 \mathrm{~h})$, a utilização de placas de fundo horizontal e do meio RPMI 1640 (Gibco) sem bicarbonato de sódio, com o tampão MOPS (Acros Organics), agora suplementado com $2 \%$ de glicose. Assim, no final, cada orifício recebeu o inóculo, o meio de cultura líquido e as soluções dos extratos brutos diluídos, de tal forma que o volume final de cada orifício fosse de $200 \mu \mathrm{L}$.

As microplacas foram lidas espectrofotometricamente após 24 h de incubação com o auxílio de um leitor de microplacas (ASYS, Eugendorf, Salzburg, Áustria) em um comprimento de onda de 450 nm. Cada poço obteve, assim, sua própria leitura de absorvância.
Usando a padronização do EUCAST para a determinação das CIM, foram incubadas também placas contendo apenas os extratos de $A$. indica e de própolis verde e RPMI 1640 2\% G. O volume de inóculo não foi adicionado, sendo substituído pelo mesmo volume de caldo RPMI $16402 \%$ G. O valor do ponto final (end point) para leitura da CIM foi conseguido baseado no crescimento de leveduras, que se deu no poço contendo apenas meio de cultura e inóculo, onde o microrganismo pôde ter $100 \%$ de crescimento. Segundo a metodologia do EUCAST, ${ }^{8}$ o ponto final da CIM é considerado onde se obteve uma leitura com absorvância igual ou inferior a $50 \%$ em comparação ao poço livre dos produtos a serem avaliados, onde houve o crescimento da levedura, ou seja, o controle positivo.

Os resultados obtidos foram submetidos às análises estatísticas segundo o teste de correlação de Spearman e ao método de Wilcoxon.

\section{RESULTADOS E DISCUSSÃO}

A Tabela 1 relaciona os resultados obtidos in vitro frente às diferentes cepas avaliadas. A análise das medianas das CIM dos extratos frente às diferentes cepas de Candida spp. revelou diferenças pouco significativas entre as duas metodologias (CLSI: 640 a $1440 \mu \mathrm{g} / \mathrm{mL}$; EUCAST: 640 a $1600 \mu \mathrm{g} / \mathrm{mL}$ ), sendo que os melhores resultados foram observados para C. albicans (isolada de paciente de hemodiálise) com uma CIM de $640 \mu \mathrm{g} / \mathrm{mL}$.

Os isolados de $C$. albicans de indivíduos doadores de sangue demonstraram uma maior resistência, quando comparados às amostras de isolados de indivíduos hemodialisados (Tabela 1).

Em nosso estudo, as cepas de $C$. albicans (ATCC 90028), $C$. parapsilosis (22019) e C. krusei (ATCC 6258) demonstraram maior susceptibilidade frente ao extrato bruto de própolis verde em comparação com o extrato bruto de $A$. indica. Os isolados de $C$. albicans oriundos dos indivíduos hígidos doadores de sangue, com exceção de

Tabela 1. Concentração Inibitória Mínima (CIM) in vitro dos extratos de A. indica (nim), de própolis verde e do fluconazol, frente a 17 amostras de Candida sp, conforme os procedimentos de microdiluição em caldo recomendados pelo CLSI M27-A2 e pelo AFST-EUCAST E.Dis. 7.1

\begin{tabular}{|c|c|c|c|c|c|c|}
\hline \multirow{2}{*}{ Microrganismo } & \multicolumn{3}{|c|}{ CLSI Mediana em $\mu \mathrm{g} / \mathrm{mL}$} & \multicolumn{3}{|c|}{ EUCAST Mediana em $\mu \mathrm{g} / \mathrm{mL}$} \\
\hline & A. indica & Própolis verde & Fluconazol & A. indica & Própolis verde & Fluconazol \\
\hline C. albicans ATTC 90028 & 1280 & 1040 & 1 & 1200 & 960 & 1 \\
\hline C. parapsilosis - ATCC 22019 & 1200 & 1120 & 2 & 1200 & 1040 & 1 \\
\hline C. krusei - ATCC 6258 & 960 & 720 & 32 & 880 & 640 & 32 \\
\hline C. albicans $^{\mathrm{a}}$ & 1120 & 1200 & 0,25 & 1120 & 1040 & 0,25 \\
\hline C. albicans $\mathrm{a}^{\mathrm{a}}$ & 720 & 1440 & 0,25 & 720 & 1360 & 0,25 \\
\hline C. albicans $\mathrm{a}^{\mathrm{a}}$ & 1360 & 1120 & 0,25 & 1280 & 1040 & 0,25 \\
\hline C. albicans $\mathrm{a}^{\mathrm{a}}$ & 640 & 960 & 0,25 & 640 & 960 & 0,25 \\
\hline C. albicans $^{\mathrm{a}}$ & 1040 & 1040 & 0,50 & 1040 & 960 & 0,50 \\
\hline C. krusei $^{\mathrm{a}}$ & 1120 & 960 & 32 & 960 & 880 & 32 \\
\hline C. krusei $i^{\mathrm{a}}$ & 960 & 1120 & 32 & 880 & 1280 & 16 \\
\hline C. parapsilosis ${ }^{\mathrm{a}}$ & 1360 & 1440 & 0,50 & 1360 & 1600 & 0,25 \\
\hline C. parapsilosis ${ }^{\mathrm{a}}$ & 1280 & 1200 & 0,50 & 1120 & 1200 & 0,50 \\
\hline C. albicans $\mathrm{s}^{\mathrm{b}}$ & 1200 & 1280 & 2 & 1120 & 1200 & 1 \\
\hline C. albicans ${ }^{\mathrm{b}}$ & 1280 & 1280 & 0,25 & 1280 & 1280 & 0,25 \\
\hline C. albicans ${ }^{\mathrm{b}}$ & 1360 & 880 & 0,50 & 1360 & 720 & 0,50 \\
\hline C. albicans ${ }^{\mathrm{b}}$ & 1360 & 880 & 0,125 & 1360 & 880 & 0,125 \\
\hline C. albicans $^{\mathrm{b}}$ & 1280 & 1280 & 2 & 1280 & 1280 & 2 \\
\hline
\end{tabular}

a: cepas isoladas de indivíduos submetidos à hemodiálise; ${ }^{\text {b}}$ : cepas isoladas de indivíduos hígidos doadores de sangue. 
duas amostras para a própolis verde, demonstraram uma sensibilidade diminuída frente aos extratos, quando comparados aos indivíduos hemodialisados. $\mathrm{O}$ extrato de própolis verde, de maneira geral, demonstrou uma tendência a ser mais efetivo que o extrato de $A$. indica frente às leveduras de Candida sp, embora estatisticamente isto seja insignificante. As cepas e os isolados de C. krusei demonstraram a esperada resistência ao controle positivo fluconazol (Tabela 1).

Com relação ao tempo de incubação, nas leituras feitas em $24 \mathrm{~h}$ (EUCAST) e em $48 \mathrm{~h}$ (CLSI), os valores de CIM frente aos extratos de $A$. indica e de própolis verde foram praticamente os mesmos, segundo análises estatísticas.

A metodologia proposta pelo EUCAST tem a vantagem de reduzir o tempo de incubação para a obtenção dos resultados nos testes de susceptibilidade aos antifúngicos. A suplementação de glicose e um inóculo de leveduras mais denso potencializaram o ciclo de crescimento da Candida sp avaliadas depois de $24 \mathrm{~h}$ de incubação. O procedimento de colocar placas contendo apenas os extratos de $A$. indica e de própolis verde em caldo RPMI 1640 com $2 \%$ de glicose, sem a adição do inóculo e substituído pelo mesmo volume desse suplemento foi necessário, devido ao fato das soluções dos extratos apresentarem certo grau de coloração e principalmente por serem soluções com densidade suficiente para que ocorresse precipitação no fundo dos poços. Assim, cada poço das placas contendo sua respectiva diluição do extrato passou a ter o seu próprio valor de corte na leitura espectrofotométrica, ou seja, o seu próprio valor de branco. Segundo os testes de correlação de Spearman e de Wilcoxon a determinação do end point espectrofotométrico feito com $24 \mathrm{~h}$ de incubação mostrou uma forte correlação com a metodologia proposta pelo CLSI, onde a leitura foi realizada visualmente com a adição de resazurina somente $48 \mathrm{~h}$ após a incubação.

Estudos têm demonstrado o valor da automatização nas leituras espectrofotométricas nos testes de susceptibilidade aos antifúngicos, pois oferece a vantagem de se obter uma leitura mais objetiva para a determinação da CIM. ${ }^{14,33}$

Apesar de não ter sido notado neste trabalho, o crescimento trailing é de grande relevância para a determinação da CIM, onde sua interpretação subjetiva deve ser considerada, haja vista que, mesmo com o uso de um agente revelador como a resazurina, as nuances de cores entre o azul e o vermelho podem ocasionar dúvidas na determinação da CIM. Assim, o EUCAST considera como CIM o orifício onde haja um crescimento de inóculo, determinado pela sua absorvância, de 50\% ou menos em relação ao controle positivo. Deve-se levar em conta que neste mesmo orifício ainda possam existir leveduras (efeito fungistático) que, ao reagirem com a resazurina, assumam uma coloração azul avermelhada. Talvez esse fato explique a diferença de leituras obtidas entre os dois métodos empregados, onde os valores de CIM determinados pela metodologia preconizada pelo EUCAST foram, em geral, menores que aqueles obtidos pelo método do CLSI.

Neste trabalho foi usado um comprimento de onda de $450 \mathrm{~nm}$ pela metodologia do EUCAST na determinação da CIM, sendo que em alguns casos, a concentração dos extratos nos poços foi alta suficiente para superar a linearidade do aparelho leitor de microplacas. Este fato não alterou a leitura das microplacas, haja vista que a leitura da absorvância compatível para a CIM, nestes casos, foi conseguida em orifícios com diluições menores.

Outro dado importante a ser relatado diz respeito à quantidade final de DMSO em cada orifício das microplacas. As metodologias do CLSI e do EUCAST utilizam 0,5\% de DMSO como concentração final. Segundo Cuenca-Estrella et al. ${ }^{34}$ embora $1 \%$ de DMSO pudesse ser utilizado, o controle positivo fluconazol usado neste experimento teve como concentração máxima de DMSO apenas $0,5 \%$ no primeiro poço antes de ser diluída. É exatamente o que ambas as metodologias usam como concentração final deste solvente. Para os extratos, foram usadas concentrações de DMSO, no máximo de $2 \%$, a qual, segundo o controle de diluição feito para o solvente, não causou nenhuma inibição para a leitura da CIM.

As faixas da CIM para a cepa de C. parapsilosis utilizada como controle de sensibilidade ao fluconazol e de C. krusei usada como controle de resistência a este mesmo agente antifúngico mostraram uma concordância com o esperado. ${ }^{35}$

\section{CONCLUSÕES}

Considerando os resultados obtidos neste trabalho e com base nas condições experimentais, podemos concluir que não houve diferença estatisticamente significante entre a eficácia dos dois extratos, embora o extrato de própolis verde tenha demonstrado melhor atividade. Os resultados de CIM obtidos pelos procedimentos preconizados pelo CLSI e pelo EUCAST possuem uma boa concordância entre si, sendo que a metodologia do EUCAST se presta para avaliar a atividade antifúngica de extratos naturais em um menor tempo, demonstrando resultados equivalentes aos do CLSI.

\section{AGRADECIMENTOS}

Ao responsável pelo Laboratório de Análises Clínicas da Universidade de Franca por ter fornecido os isolados clínicos de Candida $\mathrm{sp}$, os quais são mantidos congelados na bacterioteca do setor de microbiologia. Ao Prof. Dr. J. K. Bastos da FCFRP-USP pelo fornecimento da amostra de própolis verde.

\section{REFERÊNCIAS}

1. Rex, J. H.; Pfaller, M. A.; Walsh, T. J.; Chaturvedi, V.; Espinel-Ingroff, A.; Ghannoum, M. A.; Gosey, L. L.; Odds, F. C.; Rinaldi, M.; Sheehan, D. J.; Warnock, D. W.; Clin. Microbiol. Rev. 2001, 14, 643.

2. Gulluce, M.; Aslan, A.; Sokmen, M.; Sahin, F.; Adiguzel, A.; Agar, G.; Sokmen, A. Phytomedicine 2006, 13, 515.

3. Cordell, G. A.; Colvard, M. D.; J. Ethnopharmacol. 2005, 100, 5.

4. Passos, X. S.; Santos, S. C.; Ferri, P. H.; Fernandes, O. F. L.; Paula, T. F.; Garcia, A. C. F.; Silva, M. R. R.; Rev. Soc. Bras. Med. Trop. 2002, $35,623$.

5. Scorzoni, L.; Benaducci, T.; Almeida, A. M. F.; Silva, D. H. S.; Bolzani, V. S.; Mendes-Gianinni, M. J. S.; Braz. J. Microbiol. 2007, 38, 391.

6. Arthington-Skaggs, B. A.; Lee-Yang, W.; Ciblak, M. A.; Frade, J. P.; Brandt, M. E.; Hajjeh, R. A.; Harrison, L. H.; Sofair, A. N.; Warnock, D. W.; Antimicrob. Agents Chemother. 2002, 46, 2477.

7. Rex, J. H.; Nelson, P. W.; Paetznick, V. L.; Lozano-Chiu, M.; EspinelIngroff, A.; Anaissie, E. J.; Antimicrob. Agents Chemother. 1988, 42, 129.

8. European Committee on Antibiotic Susceptibility; Method for determination of minimal inhibitory concentration (MIC) by broth dilution of fermentative yeasts, Discussion document E. Dis. 7.1, 2002.

9. National Committee for Clinical Laboratory Standards; Reference method for broth dilution antifungal susceptibility testing of yeasts, Approved Standard M27-A2, 2 $2^{\text {nd }}$ ed., 2002.

10. Nguyen, M. H.; Yu, C. Y.; J. Clin. Microbial. 1999, 37, 141.

11. Espinel-Ingroff, A.; Pfaller, M. A.; Messer, S. A.; Knapp, C. C.; Killian, S.; Norris, H. A.; Ghannoum, M. A.; J. Clin. Microbiol. 1999, 37, 591.

12. Chryssanthou, E.; Cuenca-Estrella, M.; J. Clin. Microbiol. 2002, 40, 3841.

13. Espinel-Ingroff, A.; Dawson, K.; Pfaller, M.; Anaissie, E.; Breslin, B.; Dixon, D.; Fothergill, A.; Paetznick, V.; Peter, J.; Rinaldi, M.; Walsh, T.; Antimicrob Agents Chemother. 1995, 39, 314.

14. Odds, F. C.; Messer, S. A.; Woestenborghs, F.; Antimicrob. Agents Chemother. 1995, 39, 2051. 
15. Wall, M. E.; Wani, M. C.; J Ethnopharmacol. 1996, 51, 239

16. Rios, J. L.; Recio, M. C.; Villar, A.; J. Ethnopharmacol. 1988, 23, 127.

17. Coutinho, H. D. M.; Bezerra, D. A. C.; Lobo, K.; Barbosa, I. J. F.; Conceitos 2004, 77, 78 .

18. Vanaclocha, B.; Canigueral, S.; Fitoterapia: Vademécum de prescripción, $4^{\mathrm{a}}$ ed., Masson: Barcelona, 2003.

19. Saxena, R. C.; Inseticides of plant origin, ACS: Washington, 1989.

20. Schmutterer, H.; CRC Handbook of natural pesticides, Morgan, E. D.; Mandava, N. B., eds.; Boca Raton CRC Press: Florida, 1987, vol. 3.

21. Govindachari, T. R.; Suresh, G.; Gopalakrishnan, G.; Banumathy, B.; Masilamani, S.; Phytoparasitica 1998, 26, 1.

22. Hussain, M. A.; Gorsi, M. S.; Asian J. Plant Sci. 2004, 3, 177.

23. Fabry, W.; Okemo, P.; Ansorg, R.; Mycoses 1996, 39, 67.

24. Charmaine-Lloyd, A. C.; Menon, T.; Umamaheshwari, K.; Indian J. Pharmacol. 2005, 37, 386.

25. Lemos, M.; Barros, M. P.; Sousa, J. P.; Silva Filho, A. A.; Bastos, J. K.; Andrade, S. F.; J. Pharm. Pharmacol. 2007, 59, 603.

26. Santos, V. R.; Pimenta, F. J.; Aguiar, M. C.; Carmo, M. A.; Naves, M. D.; Mesquita, R. A.; Phytother. Res. 2005, 19, 652.

27. Leitão, D. P.; Filho, A. A.; Polizello, A. C.; Bastos, J. K., Spadaro, A. C.; Biol. Pharm. Bull. 2004, 27, 1834.
28. Estrada, E.; Quincoces, J. A.; Patlewicz, G.; Mol. Divers. 2004, 8, 21.

29. Fischer, G.; Conceição, F. R.; Leite, F. P.; Dummer, L. A.; Vargas, G. D.; Hubner, S.O.; Dellagostin, O. A.; Paulino, N.; Paulino, A. S.; Vidor, T.; Vaccine 2007, 25, 1250.

30. Marcucci, M. C.; Ferreres, F.; Garcia-Viguera, C.; Bankova, V. S.; Castro, S. L. D.; Dantas, A. P.; Valente, P. H. M.; Paulino, N.; J. Ethnopharmacol. 2001, 4, 105.

31. Bier, O.; Bacteriologia e imunologia: em suas aplicações à medicina e à higiene, Melhoramentos: São Paulo, 1981.

32. Palomino, J. C.; Martin, A.; Camacho, M.; Guerra, H.; Swings, J.; Portaels, F.; Antimicrob. Agents Chemother. 2002, 46, 2720.

33. Rodrígues-Tudela, J. L.; Martinez-Suárez, J. V.; J. Antimicrob. Chemother. 1995, 35, 739 .

34. Cuenca-Estrella, M.; Mellado, E.; Díaz-Guerra, T. M.; Monzón, A.; Rodríguez-Tudela, J. L.; Antimicrob. Agents Chemother. 2001, 45, 1905.

35. Barry, A, L.; Pfaller, M. A.; Brown, S. D.; Espinel-Ingroff, A.; Ghannoum, M. A.; Knapp, C.; Rennie, R. P.; Rex, J. H.; Rinaldi, M. G. J. Clin. Microbiol. 2000, 38: 3457. 